\title{
Nonlinear vibration analysis: analytic versus numerical methods - application to cable dynamics
}

\section{Marija Demšić}

Sveučilište u Zagrebu, Građevinski fakultet

\begin{abstract}
The analysis and prediction of the dynamic response of a nonlinear system can be very demanding because, apart from the primary resonance response, the sub- and super-harmonic responses can be induced, and if natural frequencies have integer ratio internal resonance is also possible. Mathematical analysis of such system usually requires the use of an asymptotic methods and numerical procedures. The paper presents the applications of analytical and numerical methods to nonlinear cable response, and discussion on both approaches is given.
\end{abstract}

Key words: nonlinear vibrations, asymptotic methods, numerical methods, cables

\section{Analiza nelinearnih oscilacija: analitičke naspram numeričkih metoda - primjena u dinamici kabela}

\section{Sažetak}

Analiza i predviđanje dinamičkoga odziva nelinearnoga sustava zahtjevan je zadatak, jer se osim primarne rezonancije mogu inducirati subharmonijski i superharmonijski odziv, a u slučaju cjelobrojnoga omjera prirodnih frekvencija moguća je pojava unutarnje rezonancije. Iznimno složena matematička analiza obično zahtijeva primjenu asimptotskih metoda te numeričkih postupaka proračuna. U radu je predstavljena primjena analitičkih i numeričkih metoda $u$ analizi nelinearnoga odziva kabela, te su razmotrene prednosti i mane oba pristupa.

Ključne riječi: nelinearno titranje, asimptotske metode, numerički postupci, kabeli 


\section{Introduction}

Today, scientists in the engineering sector have dedicated a lot of effort to reduce the number of approximations being introduced in mathematical model because linear analysis have become insufficient to describe the behaviour of the physical system adequately. One of the main reasons for modelling a physical system as a nonlinear one is that totally unexpected phenomena sometimes occur in nonlinear systems, phenomena that are not predicted or even hinted at by linear theory. Development of new methods and improvement of existing techniques have enabled research of these phenomena. One of the important aspects of nonlinearity are certainly nonlinear vibrations. Several methods are available for the solution of nonlinear vibration problems, like approximative analytical techniques, graphical procedures, and numerical methods. In civil engineering, nonlinear vibrations occur in many structures, especially those that are in their nature extremely flexible, low weight, and with low damping such as cable-stayed bridges or cable nets. Given the many analytical and numerical methods available today, this paper mentions several that are often used in the analysis of nonlinear cable vibrations. Analytic analysis of the nonlinear dynamic response is obtained by using a classical perturbation procedure such as the method of averaging and method of multiple scales (MMS). These methods can be directly applied to partial differential equations $[1,2,3]$, though the mathematical process itself can be more involved depending on the possible resonances of system. A more commonly used approach is performing space discretization by first applying the Galerkin reduction to obtain a system of ordinary differential equations to which perturbation analysis is applied for determining time-dependent functions [4]. By using analytical methods, it is possible to determine solutions in stable or unstable domains. Complex nonlinear responses can also be determined numerically; however, such models can only include certain bifurcation points because the numerical integration of the solution can only be determined in a stable domain [5]. The first section of paper presents the comparison of basic philosophies of both approaches without explaining the mathematical procedure needed to obtain solutions. After which the examples of relevant research in cable dynamics obtained by analytical and numerical methods are displayed, and some of advantages and disadvantages of methods are discussed.

\section{Basic philosophy}

The solution obtained by perturbation methods is formed as an expansion in which known solution, ie. solution of linear problem is supplemented by terms that represent a small corrections [6-9]. The function expansion is formed using the small perturbation parameter $\varepsilon$. Corrections need to ensure that the first correction is small 
compared to the basic unperturbed solution, then that second is small compared to the first correction and so on, all in the limit of small $\varepsilon$ [6]. Ordering is the only rule that need to hold-up for the implementation of the perturbation procedure and the construction of the asymptotic solution. By formation of perturbation hierarchy a system of equations suitable for successive solving is formed. The usual procedure for implementing a perturbation process is the formation of a nonlinear algebraic or differential equation in a non-dimensional space, after which a small parameter $\varepsilon$ is chosen based on which a perturbation solution is formed. However, there are also cases when a small parameter that would be suitable for ranking does not appear explicitly in the equation and it is necessary to model the physical system adequately. Physical understanding of the nature of problems in the modelling process is crucial for the proper formulation of a mathematical problem. Scaling of differential equation terms can have a decisive influence on the structure of the final asymptotic solution with clear connotations on accuracy and physical meaning [7]. In this case we can talk about the 'artificial' parameter of the popularly called 'bookkeeping parameter' [8-10]. This parameter introduces an implicit assumption of the influence of nonlinear coefficients, damping and excitation on system response [7]. Table 1 gives the recommendations for scaling in the analysis of parabolic cable dynamics at primary, subharmonic and superharmonic resonance [1].

Table 1. Order of first occurrence of contribution in the perturbation equations

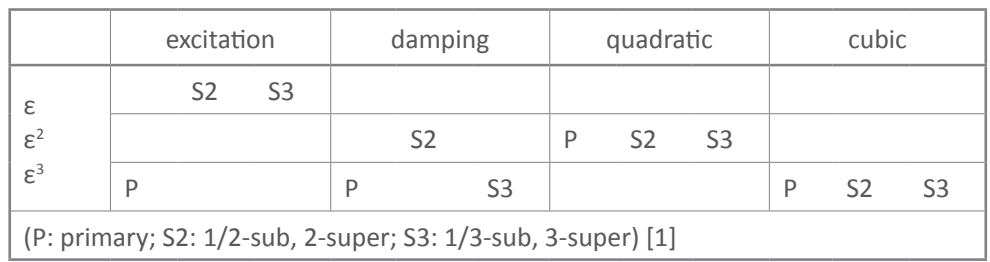

Contrary to asymptotic methods, the application of numerical methods in community of engineers and scientist is common use. Generally, for the computation of dynamic response of nonlinear system requires discretisation in space and time domain, and solution is obtained in incremental form. Finite elements of finite differences are used to describe nonlinear model in space domain. For example, by using finite elements to model cables several types of elements can be employed: axial, parabolic or catenary finite element, all comprising geometric stiffness matrix taking into account nonlinear characteristics of physical system. Catenary elements have some advantages, such as requiring fewer numbers of elements, but it also has a disadvantage: it needs to employ iterative procedures to obtain stiffness matrix [11]. Time domain integration is usually carried out using predictor-corrector technique or Runge-Kutta method. Final form of incremental solution is highly depended on space discretisation and time step. 


\subsection{Damped linear vibrations}

To present basic idea of asymptotic and numeric methods, we will use advantage of knowing exact solution of differential equation of free damped vibration:

$$
\ddot{x}(t)+\mu \dot{x}(t)+x(t)=0
$$

The basic perturbation procedure, the straightforward expansion, consists of an idea that the final solution can be written in the form of a expansion with a small perturbation parameter $\varepsilon$ :

$$
x(t, \varepsilon)=x_{0}(t)+\varepsilon x_{1}(t)+\varepsilon^{2} x_{2}(t)+\ldots+O\left(\varepsilon^{n}\right)
$$

In the case of low damping, the value of damping parameter can be used for perturbation scaling parameter $\varepsilon$.

The basic numerical integration is usually presented by Euler method, which gives incremental solution:

$$
\begin{aligned}
& x\left(t_{i}+\Delta t\right) \approx x\left(t_{i}\right)+\Delta t \cdot \dot{x}\left(t_{i}\right) \\
& \dot{x}\left(t_{i}+\Delta t\right) \approx \dot{x}\left(t_{i}\right)+\Delta t \cdot \ddot{x}\left(t_{i}\right)
\end{aligned}
$$

Comparison of this two methods with exact solution is shown in Figure 1. For asymptotic method, it can be seen that all the solutions match the exact response in the beginning of the response, but as time is increasing more correction terms are needed to take into account. The breakdown in the straightforward expansion is due to its failure to account for the nonlinear dependence of the frequency of the system on the nonlinearity. A number of techniques that yield uniformly valid expansions have been developed [8]. Some of those techniques are MMS and method of averaging also known as van der Pol method [9]. These techniques take into account that changes due to nonlinearities of the system do not happen at same time rate. In order to consider this by MMS, it needs to represent the response as a function of multiple independent variables, or scales, instead of single variable [8]:

$$
\begin{gathered}
T_{n}=\varepsilon^{n} t \text { for } n=0,1,2, \ldots \\
x(t, \varepsilon)=x_{0}\left(T_{0}, T_{1}, \ldots\right)+\varepsilon x_{1}\left(T_{0}, T_{1}, \ldots\right)+\varepsilon^{2} x_{2}\left(T_{0}, T_{1}, \ldots\right)+\ldots+O\left(\varepsilon^{n}\right)
\end{gathered}
$$


In which the number of independent time scales depends on the order to which the expansion is carried out. Solution obtained by MMS for the expansion $\varepsilon^{2}$ is shown on Figure 2a.

a) $x$

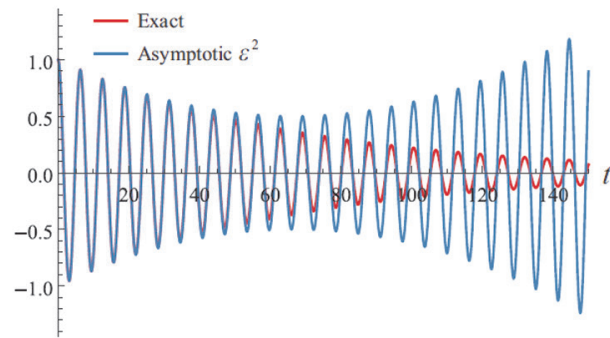

b)

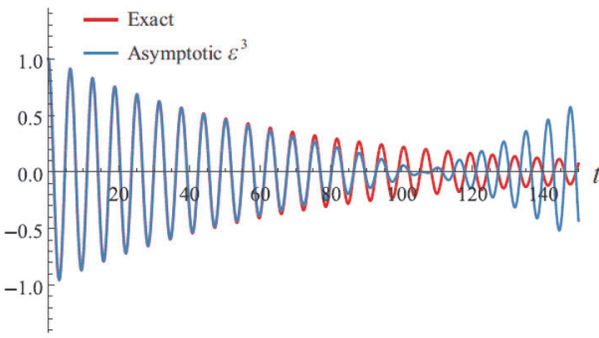

c) $x$

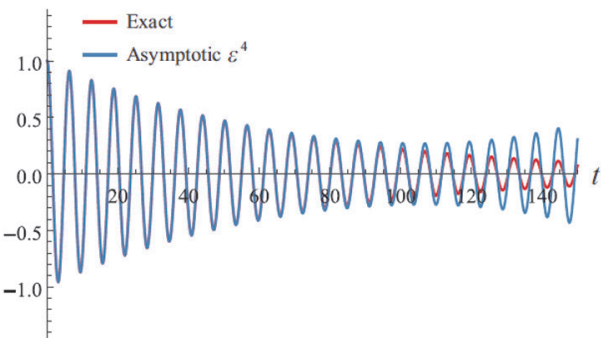

d) $x$

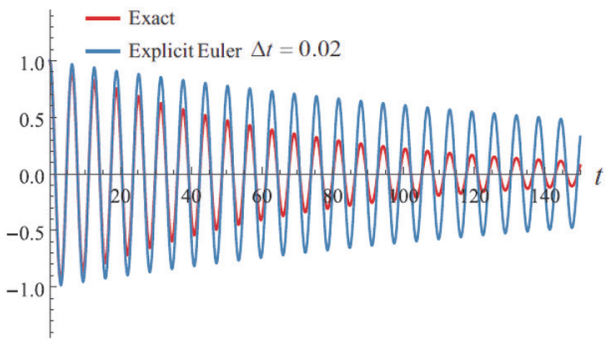

e) $x$

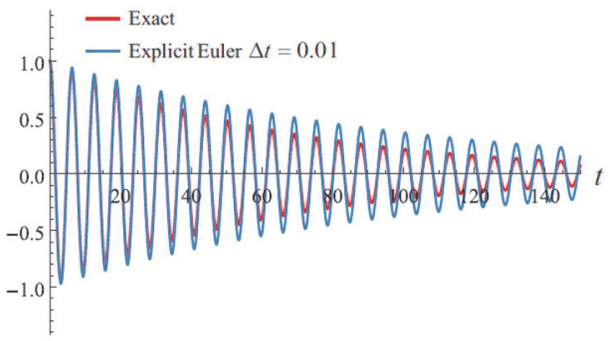

f) $x$

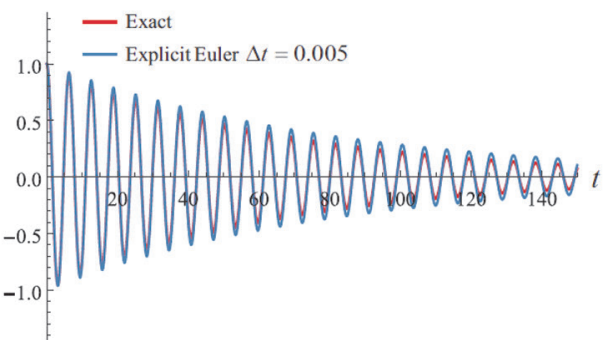

Figure 1. Response function. (a-c) Straightfoward expansion; (d-e) Euler method

Numerical solutions for different time steps are shown in Figure 1d, e and f. All responses show the growth of error that ultimately leads to a significant deviation from exact solution. Error can be further reduced by step reduction but that only increases calculation time, much more effective is to use some of the higher order methods. For example, the solution using the explicit Runge-Kutta method is shown in the Figure $2 \mathrm{~b}$. As can be seen, both procedures give satisfactory results in the case of linear system response. 


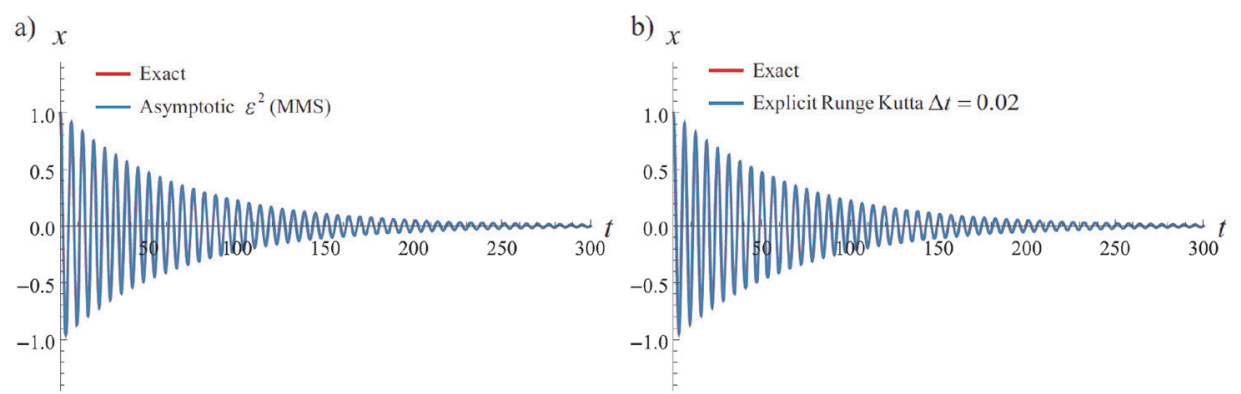

Figure 2. Response function. (a) MMS; (b) Runge-Kutta method

\section{Cable dynamics}

Nonlinear responses of a parabolic cable are of theoretical interest in applied mechanics and an archetypal model of various phenomena in dynamics [1]. Partial differential equations of cable motion are usually reduced by the Galerkin method to ordinary differential equations (ODE) that contain quadratic and cubic nonlinearities produced by the initial curvature and stretching. Frequency response curve that characterise cable response to primary resonance is displayed in Figure 3a. The figure shows asymptotic solution obtained by MMS method and two numerical solution. Solutions labelled as NI determinated by direct numerical integration of reduced ODE in Wolfram Mathematica. Calculation starts with homogeneous initial conditions, and in the subsequent calculations after a steady-state amplitude is achieved, the excitation frequency/ amplitude is changed. Other numerical model of cable is obtained by space discretisation of system using finite differences, and predictor-corrector algorithm is used for integration in time domain. The results of the finite difference model for homogeneous and nonhomogeneous initial conditions (FD-hic and FD-nic, respectively) are displayed. Nonhomogeneous conditions are set in the vicinity of the steady state determined by the MMS process. It can be seen that the results are in good agreement in the region where solution is unique but in the region where response depends on nonhomogeneous initial conditions, the numerical models have difficulty describing high-amplitude vibrations, and solution leads to curve of low amplitude vibrations. Characteristic stream plot of vector field of the initial amplitude and phase is displayed in Figure $3 \mathrm{~b}$. All initial conditions starting in the shaded area result in high-amplitude response. However, in the regions where stable and unstable curve are approaching each other the stable node (P1) and saddle point (P2) are approaching. Since numerical models are very sensitive to any perturbation in the system, the response by using these models usually led to low-amplitude vibration (P3). 
a)

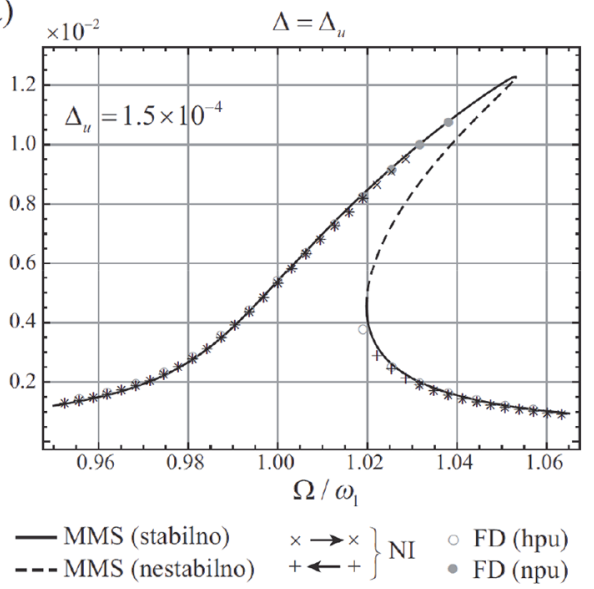

b)

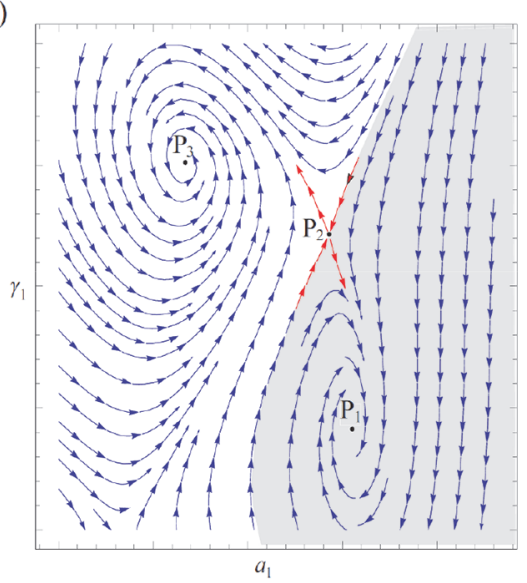

Figure 3. a) Frequency-amplitude curve at primary resonance for constant excitation amplitude [12], b) initial conditions vector field [12]

Frequency-amplitude curve due to primary resonance is well known and analysis of the solutions with analytical or numerical model gives good prediction of the final values of amplitude. Analysis that is more complicated is in the case when nonlinear interaction happens in the system response. Figure 4 display a frequency-amplitude curve for the case of interaction due to primary and parametric resonance. Frequency-amplitude curve are constructed for amplitudes $a_{1}$ and $a_{2}$ of generalized coordinates and $w_{s}$ and $w_{c}$ that denote the maximum value of nodal displacement in the middle and at a quarter of the cable span, respectively. For the construction of these curves several numerical methods were used.

Only MMS solutions that displayed by continuous line is fully analytical solution. In the case of interaction (MMS - INT) system of equations that is obtained in analytical form is solved by numerical methods using Wolfram Mathematica. Besides already mentioned $\mathrm{NI}$ and FD model, finite element (FE) results obtained using SAP2000 are shown also. All of these numerical models are used to verify analytical expressions obtained by MMS technique. In these frequency-amplitude curve it is important the emphasize solution between two Hopf bifurcation labelled by $\mathrm{H}_{1}$ and $\mathrm{H}_{2}$. It is worth noting that in this region for specific initial conditions, numerical models NI and FD have a dynamic response [4]. Thanks to numerical models, it was concluded that in that region a regular system response can exist with frequencies that match the primary and parametric resonance. A slight variation in the amplitude causes this branch to be classified as unstable, thus this response is unstable only due to nonexistence of a steady state [8]. 
a)

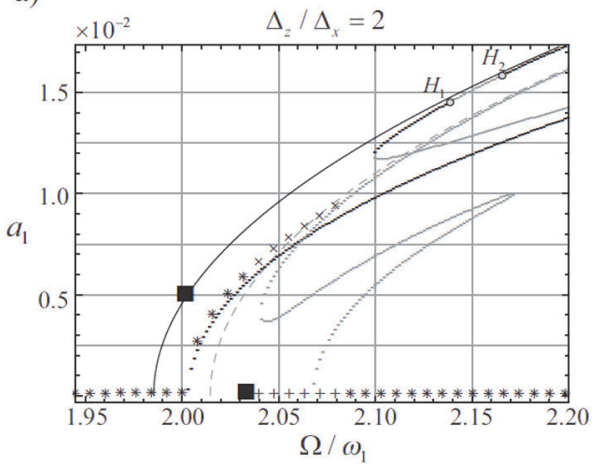

c)

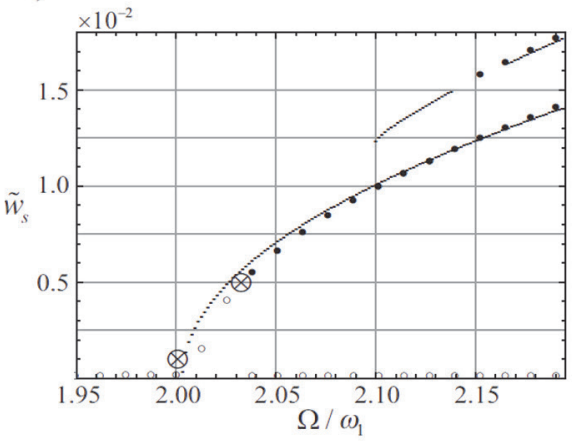

b)

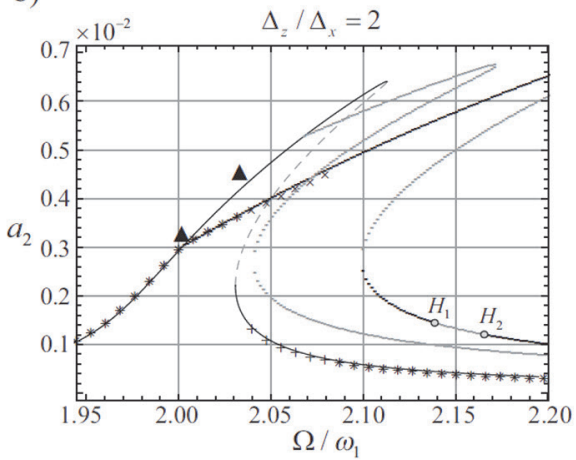

d)

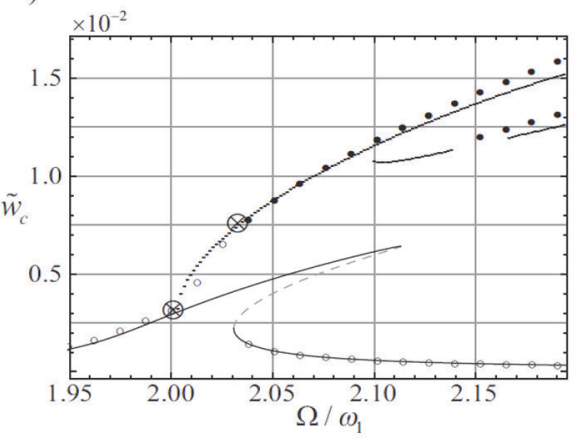

- FE - par

$\triangle \mathrm{FE}$ - forc

$\otimes \mathrm{FE}-$ int

Figure 4. Frequency-amplitude curves [4]. a) parametric resonance amplitude; b) primary resonance amplitude; c) maximum displacement in middle of cable span; d) maximum displacement in quarter of cable span

By using analytical analysis, the regions of nonlinear resonance in excitation parameter space can be easily explored (Figure 5). Boundary curves that are obtained by analytical expressions allow definition of histeresis, and high- or low-amplitude regions while results of numerical models require in depth analysis of time-history function response (steady-state amplitude, Fourier spectrum). 

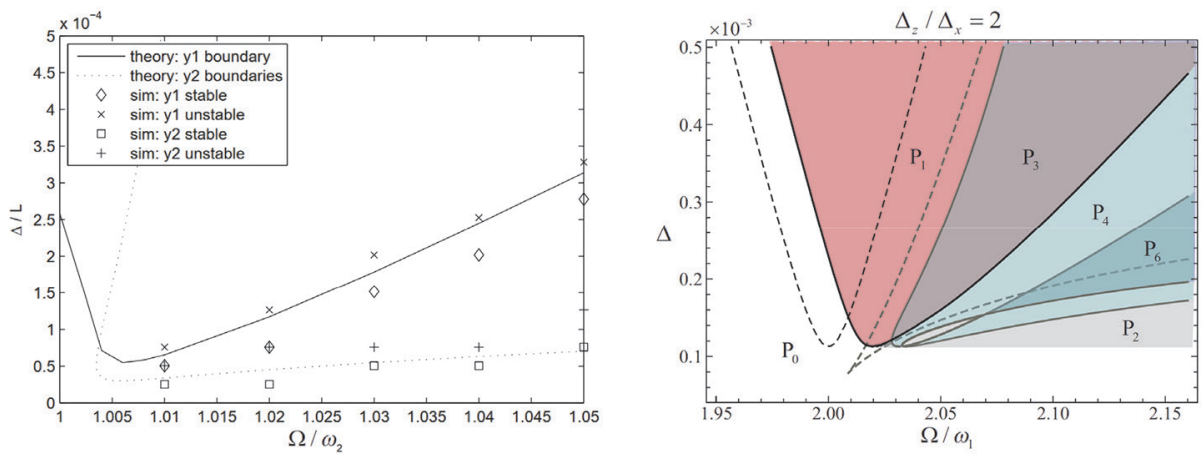

Figure 5. Resonance region due to interaction of primary and parametric resonance. a) boundaries obtained using method of averaging and numerical simulations [13]; (b) MMS [4]

\section{Conclusion}

It is important to note that analytic asymptotic methods are valid in specific frequency domain and for specific ordering in formation of perturbation hierarchy. Demanding task in the analytical approach is description of the model by continuous functions. This implies that only simple models can be analysed. However, since use of analytic modelling is not to describe a real structure even in linear theory, but for in-depth understanding of a certain nonlinear phenomena, we can argue that their use is justified or even necessary. Complex behaviour require using some kind of theoretical method, though combined with selected numerical tools, rather than generic computer simulations on large discrete models [1]. The most reliable results on theoretical analysis of nonlinear oscillations are achieved by simultaneously using analytical and numerical methods. Therefore, the analytical model offers a framework for describing the results obtained by numerical methods.

\section{References}

[1] G. Rega, Nonlinear vibrations of suspended cables - part I: modeling and analysis, Applied Mechanics Reviews 57 (6) (2004) 443-478, https://doi.org/10.1115/1.1777224

[2] G. Rega, W. Lacarbonara, A.H. Nayfeh, C.M. Chin, Multiple resonances in suspended cables: direct versus reduced-order models, International Journal of Non-Linear Mechanics 34 (1999) 901-924. https://doi.org/10.1016/S0020-7462(98)00065-1.

[3] A.H. Nayfeh, H.N. Arafat, C.M. Chin, W. Lacarbonara, Multimode interactions in suspended cables, Journal of Vibration and Control 8 (2002) 337-387, https://doi. org/10.1177/107754602023687. 
[4] M. Demšić, M. Uroš, A. Jaguljnjak Lazarević, D. Lazarević, Resonance regions due to interaction of forced and parametric vibration of a parabolic cable, Journal of Sound and Vibration 447 (2019) 78-104, https://doi.org/10.1016/j.jsv.2019.01.036

[5] V. Gattulli, L.Martinelli, F. Perotti, F. Vestroni, Nonlinear oscillations of cables under harmonic loading using analytical and finite element models, Computer Methods in Applied Mechanics and Engineering 193 (2004) 69-85, https://doi.org/10.1016/j. cma.2003.09.008.

[6] Jakobsen, P.: Introduction to the method of multiple scales. Cornell University Library, 2013. URL: http://arxiv.org/abs/1312.3651v2 (03.07.2014.)

[7] Marinca, V., Nicolae, H.: Nonlinear Dynamical Systems in Engineering, Springer-Verlag Berlin Heidelberg, 2011.

[8] Nayfeh, A.H., Mook, D.T.: Nonlinear Oscilations, John Wiley \&Sons Inc., USA, 1995.

[9] Nayfeh, A.H.: Introduction to Perturbation Techniques, John Wiley\&Sons Inc., USA, 1993.

[10] Abe, A.: On non-linear vibration analysis of continuous systems with quadratic and cubic non-linearities, International Journal of Non-linear Mechanics, Vol. 41, No. 8, 2006., pp. 873-879.

[11] M. Nikolić, V. Raduka, Numerical Investigation of Cable Parametric Vibrations, Proceedings of 11th International Conference on Vibration Problems (2013)

[12] M. Demšić, Nelinearna analiza oscilacija kabela i njihove interacije s konstrukcijom, PhD thesis, Faculty of Civil Engineering, University of Zagreb, Zagreb, 2015.

[13] A. Gonzalez-Buelga, S.A. Neild, D.J. Wagg, J.H.G. Macdonald, Modal stability of inclined cables subjected to vertical support excitation, Journal of Sound and Vibration 318 (2008) 565-579. https://doi.org/10.1016/j.jsv.2008.04.031. 